\title{
What keeps postpulmonary resection patients in hospital?
}

\author{
T Bardell BScE, D Petsikas MD FRCSC
}

T Bardell, D Petsikas. What keeps postpulmonary resection patients in hospital? Can Respir J 2003;10(2):86-89.

BACKGROUND: Prolonged air leak (longer than three days) was hypothesized to be the primary cause of extended hospital stays following pulmonary resection. Its effect on length of stay (LOS) was compared with that of suboptimal pain control, nausea and vomiting, and other causes. Predictors of prolonged LOS and of prolonged air leaks were investigated.

DESIGN: Retrospective review of 91 patients. Primary reasons for prolonged hospitalization were determined. Patient characteristics (demographic information, pulmonary function test results, body habitus measurements, smoking history), operative factors (procedure performed, duration of operation, complications) and postoperative factors (time of chest tube removal) were considered. Student's $t$ test and $\chi^{2}$ analysis were used to compare continuous and ratio data, respectively, and linear regression analysis was used to define the equation relating two variables.

RESULTS: The mean postoperative LOS was 6.4 days. Only prolonged air leak was predictive of increased LOS ( 9.4 days versus 5.4 days, $\mathrm{P}<0.001)$. Forced expiratory volume in $1 \mathrm{~s}$ less than $1.5 \mathrm{~L} / \mathrm{min}$, carbon monoxide diffusing capacity less than $80 \%$ predicted and the detection of a pneumothorax were all predictive of prolonged air leak. A strong correlation between the time of chest tube removal and LOS was found $(r=0.937, \mathrm{P}<0.001)$. Linear regression analysis showed postoperative LOS and duration of thoracostomy tube insertion to be related by the equation $y=0.88 x+2.49$ days.

CONCLUSION: These results suggest that increased LOS following pulmonary resection is due primarily to prolonged air leaks. Furthermore, patients who have their chest tubes removed sooner are discharged sooner.

Key Words: Length of stay; Pneumonectomy; Pneumothorax; Thoracotomy

\section{Qu'est-ce qui maintient les patients à l'hôpital après une résection pulmonaire?}

HISTORIQUE : L'effet d'une fuite d'air prolongée (de plus de trois jours), qu'on croit être la principale cause d'hospitalisation prolongée après une résection pulmonaire, sur la durée d'hospitalisation (DH) a été comparé au contrôle sous-optimal de la douleur, aux nausées et aux vomissements et à d'autres causes. Les prédicteurs de DH et de fuites d'air prolongées ont été explorés.

MÉTHODOLOGIE : Étude rétrospective de 91 patients. Les principales raisons de l'hospitalisation prolongée ont été établies. Les caractéristiques des patients (information démographique, résultats de l'exploration fonctionnelle respiratoire, mesures des phénotypes organiques, antécédents de tabagisme), les facteurs de l'opération (intervention exécutée, durée de l'opération, complications) et les facteurs postopératoires (moment du retrait du drain thoracique) ont été évalués. L'analyse des essais $t$ et $\chi^{2}$ des chercheurs a été utilisée pour comparer les données continues et de coefficient, respectivement, et une analyse de régression linéaire a permis de définir l'équation reliant deux variables.

RÉSULTATS : La principale DH postopératoire était de 6,4 jours. Seule une fuite d'air prolongée était prédictive d'une $\mathrm{DH}$ plus longue $(9,4$ jours par rapport à 5,4 jours, $\mathrm{P}<0,001)$. Un volume expiratoire maximal par seconde inférieur à $1,5 \mathrm{~L} / \mathrm{min}$, une capacité de diffusion pulmonaire à moins de $80 \%$ de celle prévue et la détection d'un pneumothorax étaient tous prédictifs d'une fuite d'air prolongée. Une forte corrélation entre le moment du retrait du drain thoracique et la $\mathrm{DH}$ a été observée $(\mathrm{r}=0,937$, $\mathrm{P}<0,001)$. L'analyse de régression linéaire a démontré que la $\mathrm{DH}$ postopératoire et la durée de l'insertion d'un drain de thoracotomie sont reliées par l'équation $y=0,88 x+2,49$ jours.

CONCLUSION : Ces résultats indiquent qu'une DH prolongée par suite d'une résection pulmonaire est principalement imputable à des fuites d'air prolongées. De plus, les patients dont le drain thoracique est retiré plus rapidement obtiennent leur congé de l'hôpital plus rapidement.

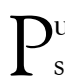
ulmonary resections are among the most common thoracic surgery procedures, which, despite recent advances, can often result in considerable morbidity. The thoracotomy incision can cause considerable postoperative pain, and both intravenous and epidural opioids are commonly used for pain control. Pain treatment regimens can be associated with problems such as poor pain control, nausea and vomiting, and constipation. Air leaks and mediastinal bleeding are also common problems following pulmonary resection, and thoracostomy tubes are universally used for evacuation of blood and air from the chest cavity.
The mean postoperative length of stay (LOS) is usually reported to be between five and seven days for patients that have undergone pulmonary resection (1-3). In cases in which complications arise, hospital stays can be much longer, resulting in increased morbidity and cost. Considerable effort has been invested to determine factors that are predictive of morbidity following pulmonary resection. Research efforts have been primarily directed at predictors of pulmonary complications. Complications considered include prolonged ventilation, reintubation, hypoxemia, carbon dioxide retention, atelectasis and pneumonia. Spirometry, exercise oximetry, car-

This study was presented at the American College of Chest Physicians 2001 Annual Meeting, November 4 to 8, 2001, Philadelphia,

Pennsylvania, USA

Department of Surgery, Queen's University, Kingston, Ontario

Correspondence: Dr Dimiti Petsikas, Kingston General Hospital, Division of Cardiothoracic Surgery, 76 Stuart Street, Kingston, Ontario

K7L 2V6. Telephone 613-548-2383, fax 613-549-2902, e-mail fargoc@post.queensu.ca 
TABLE 1

Predictors of increased length of stay (LOS) postpulmonary resection

\begin{tabular}{lll}
$\begin{array}{l}\text { Patient } \\
\text { characteristics }\end{array}$ & Operative factors & Postoperative factors \\
\hline $\begin{array}{l}\text { Age } \\
\begin{array}{l}\text { Pulmonary function } \\
\text { test results }\end{array}\end{array}$ & $\begin{array}{l}\text { Procedure } \\
\text { Duration of operation }\end{array}$ & $\begin{array}{r}\text { Time of chest tube removal } \\
\text { Reason cited for increased } \\
\text { Marital status }\end{array}$ \\
$\begin{array}{l}\text { Body habitus } \\
\text { Sex }\end{array}$ & $\begin{array}{l}\text { Pathological diagnosis } \\
\text { Intraoperative complications }\end{array}$ \\
Smoking history & \\
\hline
\end{tabular}

TABLE 3

Reasons for prolonged stay postpulmonary resection

\begin{tabular}{lrcc}
\hline $\begin{array}{l}\text { Reason for increased } \\
\text { length of stay }\end{array}$ & $\mathbf{n}$ & Mean (days) & P \\
\hline All patients & 91 & 6.4 & \\
Prolonged air leak & 27 & 9.4 versus 5.2 & $<0.001$ \\
Nausea and vomiting & 4 & 6.2 versus 6.5 & 0.87 \\
Poor pain control & 15 & 5.9 versus 6.6 & 0.59 \\
Other & 26 & 7.5 versus 6.1 & 0.143 \\
No reason found & 31 & 4.0 versus 7.7 & $<0.001$ \\
\hline
\end{tabular}

*Mean length of stay for those with the reason listed versus those without (Note: Some patients had extended stays for more than one reason)

bon monoxide diffusion capacity, blood gases and complicated scoring systems involving combinations of these variables are some of the predictors that have been investigated $(1,4-9)$.

Studies that have looked at prolonged air leak (PAL) as a complication of pulmonary resection surgery typically define PAL as an air leak persisting for at least seven days $(2,7,9)$. Because many patients do not have air leaks that last this long (or do not have air leaks at all), we believe that any air leak that lasts longer than three days should be considered a PAL. Furthermore, because mean LOSs are often reported to be seven days or less, any study that defines PAL as an air leak lasting longer than seven days is almost assured at the outset of finding PAL to be predictive of increased postoperative LOS.

In the present study, we sought to determine the effect of PAL (defined as longer than three days) on postoperative LOS; to compare PAL to nausea and vomiting, poor pain control and other causes of increased LOS; to assess the predictive value of patient characteristics and operative factors on both LOS and the occurrence of a PAL; and to determine the relationship between the time of thoracostomy tube removal and postoperative LOS.

\section{PATIENTS AND METHODS}

\section{Patients}

A retrospective review of 100 charts was conducted for patients who underwent pneumonectomy, lobectomy, bilobectomy, bullectomy or wedge resection between January 1998 and April 2000 at Kingston General Hospital, Kingston, Ontario. The patients were selected randomly (by hospital patient identification number) from 178 patients during the above stated time period. Only records for patients who were older than 18 years of age and had undergone pulmonary resection were considered.
TABLE 2

Comparison of length of stay postpulmonary resection by pathology

\begin{tabular}{|c|c|c|c|}
\hline Pathology & $n$ & Mean (days) ${ }^{\star}$ & $\mathbf{P}$ \\
\hline All patients & 91 & 6.4 & \\
\hline All malignacies & 62 & 7.0 versus 5.1 & 0.021 \\
\hline \multicolumn{4}{|l|}{ Malignant conditions } \\
\hline Squamous cell & 16 & 6.9 versus 6.4 & 0.74 \\
\hline Adenocarcinoma & 35 & 7.6 versus 5.7 & 0.032 \\
\hline Large cell & 5 & 7.4 versus 6.4 & 0.32 \\
\hline \multicolumn{4}{|l|}{ Benign diseases } \\
\hline Pneumothorax & 12 & 5.8 versus 6.7 & 0.63 \\
\hline Granuloma & 8 & 5.0 versus 6.6 & 0.143 \\
\hline Other benign disease $^{\dagger}$ & 9 & 4.6 versus 6.7 & 0.002 \\
\hline
\end{tabular}

*Mean length of stay for those with the pathological condition versus those without; 'Sarcoidosis, bullet removal, cystic bronchiectasis, hematoma, interstitial fibrosis, mycobacterium infection, right middle lobe syndrome, histoplasmosis, abscess

Data collection

Factors considered to be possible predictors of increased LOS are listed in Table 1. Postoperative factors considered were time of chest tube removal and reason for increased LOS as summarized on the discharge record. If this was not clearly specified, the reason for increased LOS (longer than three days) was inferred from the progress notes. The outcome measured was postoperative LOS. Mean LOS was determined, along with 95\% CIs, for each variable.

Statistical analysis

Statistical calculations were performed using SPSS version 10 (SPSS Inc, USA). Student's $t$ test was performed to determine the relationship between the above factors and LOS. Correlation functions were performed for LOS and duration of thoracostomy insertion, pulmonary function test results and number of packyears of smoking. To determine which factors were predictive of PALs, $\chi^{2}$ analyses were performed. Linear regression was performed for factors deemed to be significant following correlation analysis.

Patient characteristics

\section{RESULTS}

Of the 100 pulmonary resection patients selected for review, 91 met the inclusion criteria for the study. The mean age of patients was $56.3 \pm 3.1$ years (range 18 to 82 years), with 18 patients aged 70 years or older. Of the 91 included patients, 38 were women $(42 \%)$ and 53 were men (58\%). Ninety per cent had a history of cigarette smoking. The pathological diagnoses are listed in Table 2. Procedures included 12 pneumonectomies, 38 lobectomies and 39 wedge resections. Bullectomies were performed 10 times (four of which were performed by video-assisted thoracic surgery).

\section{Factors contributing to increased LOS}

The reasons for increased LOS are summarized in Table 3. The mean postoperative LOS for all patients was 6.4 days. Patients noted to have a PAL had a significantly increased LOS (9.4 versus 5.2 days, $\mathrm{P}<0.001)$. LOS was not influenced by the type of pulmonary resection performed (wedge resection, lobecto- 
TABLE 4

Postoperative complications and length of stay (LOS) postpulmonary resection

\begin{tabular}{lcrc}
\hline Complication & $\mathbf{n}$ & Mean (days) $^{\star}$ & P \\
\hline Pneumothorax any time on CXR & 37 & 7.5 versus 5.8 & 0.06 \\
Pneumothorax on postoperative CXR & 25 & 7.8 versus 5.9 & 0.049 \\
Subcutaneous emphysema & 41 & 7.3 versus 5.8 & 0.08 \\
Atelectasis & 20 & 6.9 versus 6.3 & 0.66 \\
Reoperation & 6 & 16.8 versus 5.7 & $<0.001$ \\
\hline
\end{tabular}

*Mean LOS for those with the complication listed versus those without. CXR Chest $\mathrm{x}$-ray

TABLE 5

Patient characteristics: Prolonged air leak (PAL) versus no PAL

\begin{tabular}{lccc}
\hline Characteristic & $\begin{array}{c}\text { Number } \\
\text { with PAL }\end{array}$ & $\begin{array}{c}\text { Percentage } \\
\text { with PAL }\end{array}$ & P \\
\hline Malignancy & $21 / 62$ & $33 \%$ versus $21 \%$ & 0.43 \\
Female & $13 / 37$ & $35 \%$ versus $25 \%$ & 0.35 \\
Smoker & $22 / 74$ & $30 \%$ versus $44 \%$ & 0.36 \\
Mean age (years) & 27 & 59 versus 55 years & 0.25 \\
\hline
\end{tabular}

*Percentage with PAL for those with the characteristic listed versus those without

my, pneumonectomy, bilobectomy or bullectomy). Patients with a diagnosis of cancer had longer stays than those with benign disease $(7.0$ versus 5.1 days, $\mathrm{P}=0.021)$. Table 2 shows the mean LOS according to pathological diagnosis. Pneumothorax on postoperative chest radiograph, the occurrence of an air leak at any time during the stay and the need for reoperation were all factors predictive of increased LOS (Table 4). LOS was not influenced by smoking history, operative complications, body mass index or body surface area. A weak correlation between age and LOS was found $(r=0.245$, $\mathrm{P}=0.017$ ). A strong correlation between the time of chest tube removal and LOS was found $(r=0.903, \mathrm{P}<0.0001)$. This correlation is stronger when pneumonectomy is excluded $(r=0.937$, $\mathrm{P}<0.0001)$. The postoperative LOS can be predicted by the equation $y=0.88 x+2.49$, in which $x$ is the day of chest tube removal (Figure 1). A carbon monoxide diffusion capacity of less than $80 \%$ was predictive of increased LOS ( 7.9 versus 5.8 days, $\mathrm{P}=0.03$ ), but forced vital capacity (FVC), forced expiratory volume in $1 \mathrm{~s}\left(\mathrm{FEV}_{1}\right), \mathrm{FEV}_{1} / \mathrm{FVC}$ and total lung capacity were not. Women had a significantly longer stay following pulmonary resection than men $(7.5$ versus 5.6 days, $\mathrm{P}=0.037)$.

Factors predictive of PAL

Of the 27 patients noted to have an air leak on the third postoperative day or later, 14 were men and 13 were women. The average age was 59 years (range 18 to 82 years). Patient characteristics were similar in both groups (Table 5). Pneumothorax on chest radiograph and an $\mathrm{FEV}_{1}$ less than $1.5 \mathrm{~L} / \mathrm{min}$ were predictive of PAL (Table 6).

\section{DISCUSSION}

In the present study, air leaks lasting at least three days were found to be associated with increased LOS following pulmonary resection. Nausea and vomiting, poor pain control,

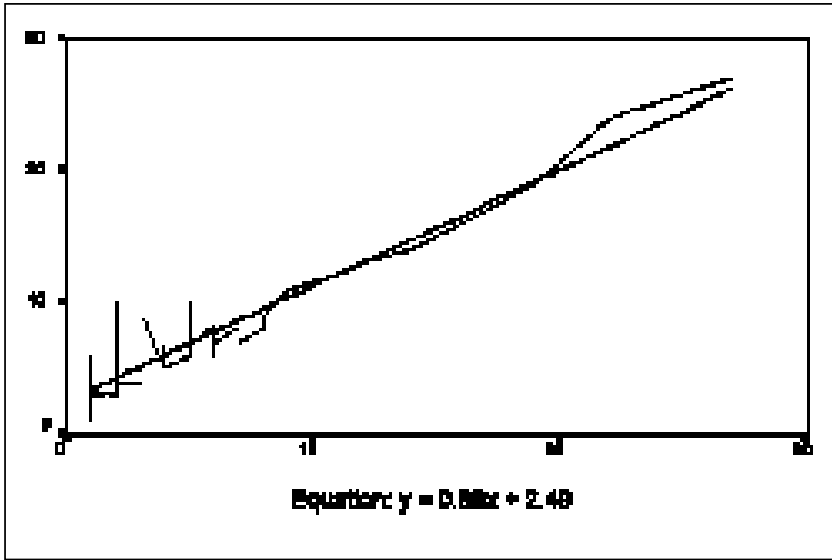

Figure 1) Relationship between time of chest tube removal (days) and length of stay (days) for all procedures excluding pneumonectomy

\section{TABLE 6}

Analysis of subpopulation with prolonged air leak (PAL)

\begin{tabular}{lccc}
\hline Predictor & $\begin{array}{c}\text { Number } \\
\text { with PAL }\end{array}$ & $\begin{array}{c}\text { Percentage } \\
\text { with PAL* }\end{array}$ & P \\
\hline $\begin{array}{l}\text { Pneumothorax on chest radiograph } \\
\quad \text { postoperative day } 1\end{array}$ & 10 & $40 \%$ versus 26\% & 0.18 \\
Pneumothorax any time & 16 & $43 \%$ versus 20\% & 0.019 \\
FEV $_{1}<1.5 \mathrm{~L} / \mathrm{min}$ & 4 & $67 \%$ versus 25\% & 0.048 \\
FEV $_{1} / \mathrm{FVC}<60 \%$ & 7 & $35 \%$ versus $15 \%$ & 0.068 \\
DLCO $<80 \%$ predicted & 12 & $41 \%$ versus $19 \%$ & 0.06 \\
\hline
\end{tabular}

${ }^{*}$ Percentage with PAL for those with the characteristic listed versus those without. FEV 1 Forced expiratory volume in $1 \mathrm{~s}$; FVC Forced vital capacity; DLCO Carbon monoxide diffusion capacity

and other possible reasons such as constipation, anxiety and depression were not related to increased stay. Correlation analysis demonstrated that when pneumonectomy is excluded, LOS can be linked to PAL by the equation $y=0.88 x+2.49$. This result suggests that patients who have their chest tubes removed sooner are discharged sooner.

Other investigators found that male sex, advanced age, pneumothorax on the first postoperative day and $\mathrm{FEV}_{1} / \mathrm{FVC}$ less than $60 \%$ were predictors of PALs, but these results were not reproduced here $(2,3,10)$. In this study, the discovery of a pneumothorax on chest radiograph at any time during the hospital stay was found to be predictive of PALs, as was an $\mathrm{FEV}_{1}$ of less than $1.5 \mathrm{~L} / \mathrm{min}$. These results concur with those previously reported. Our findings also concur with those of Abolhoda et al (2), in that a significant difference in the LOS was found for patients that had an air leak for longer than seven days. Rather than defining a PAL as any leak lasting longer than seven days, we chose a cut-off of three days. Many patients are discharged as early as two or three days after pulmonary resection. In defining a PAL to be any air leak longer than the median LOS, a statistically significant increase in LOS for patients with a PAL is the only plausible result.

Patients with benign disease had shorter LOSs than those with malignancies. This may reflect a lesser degree of sys- 
temic illness in this subset of patients. Female sex was also found to be weakly associated with a longer stay. This finding has not been consistently observed in patients undergoing pulmonary resection. It has, however, been a well-described occurrence for patients undergoing coronary artery bypass surgery $(11,12)$.

The present study was also limited by small sample size, resulting in insufficient power to limit the possibility of falsenegative results. There are also the usual limitations of a retrospective review, such as incomplete charting. Despite these limitations, it is clear from the results that air leaks are an important cause of increased LOSs. This study has demonstrated that patients noted to have a PAL have a significantly increased LOS. Further evidence that a PAL causes an increased LOS was provided by the linear relationship demonstrated between the time of chest tube removal and LOS. It is important to note that chest tubes are left in place for prolonged fluid drainage, as well as for air leaks. In the present study, we did not differentiate between these reasons for leaving a chest tube in. Poor carbon monoxide diffusion

\section{REFERENCES}

1. Wang J, Olak J, Ultmann RE, et al. Assessment of pulmonary complications after pulmonary resection. Ann Thorac Surg 1999;67:1444-7.

2. Abolhoda A, Liu D, Brooks A, et al. Prolonged air leak following radical upper lobectomy. Chest 1998;113:1507-10.

3. Hazelrigg SR, Nunchuk SK, LoCicero J, et al. Video assisted thoracic surgery study group data. Ann Thorac Surg 1993;56:1039-44.

4. Keagy BA, Schorlemmer GR, Murray GF, et al. Correlation of preoperative pulmonary function testing with clinical course in patients after pneumonectomy. Ann Thorac Surg 1983;36:253-7.

5. Ninan M, Sommers KE, Landreneau RJ, et al. Standardized exercise oximetry predicts postpneumonectomy outcome. Ann Thorac Surg 1997;64:328-33.

6. Olsen GN, Bolton JWR, Weiman DS, et al. Stair climbing as an exercise test to predict the postoperative complications of pulmonary resection. Chest 1991;99:587-90.

7. Keagy BA, Lores ME, Starek PJK, et al. Elective pulmonary lobectomy: factors associated with morbidity and operative mortality. Ann Thorac Surg 1985;40:349-52.

8. Busch E, Verazin G, Antkowiak JG, et al. Pulmonary complications in patients undergoing thoracotomy for lung carcinoma. Chest 1994;105:760-6.

9. Ferguson MK, Little L, Rizzo L, et al. Diffusing capacity predicts morbidity and mortality after pulmonary resection. J Thorac Cardiovasc Surg 1988;96:894-900. capacity and poor $\mathrm{FEV}_{1}$ were subsequently shown to be predictive for developing a PAL.

It has been established that an increased LOS is associated with increased morbidity and cost $(13,14)$. Prevention of air leaks may translate to decreased morbidity and increased savings. Several techniques to prevent air leaks have been attempted. The use of fibrin glue and the application of bovine pericardial strips along staple lines have both been met with limited success $(15,16)$. Two techniques that show promise are the use of a new synthetic absorbable sealant and a pleural tent in patients after upper lobectomy $(17,18)$. While further studies are needed to confirm the effectiveness of these methods, they may be useful in preventing air leaks and decreasing LOSs, especially if used in the subset of patients with poor preoperative lung function.

\section{CONCLUSIONS}

We have shown that PALs are related to prolonged hospitalization after pulmonary resection. Prevention of this complication may result in decreased LOSs, decreased morbidity and decreased cost.

10. Rice TW, Kirby TJ. Prolonged air leak. Chest Surg Clin N Am 1992;2:803-11.

11. Ott RA, Gutfinger DE, Alimadian $\mathrm{H}$, et al. Conventional coronary artery bypass grafting: why women take longer to recover. J Cardiovasc Surg 2001;42:311-5.

12. Aldea GS, Gaudini JM, Shapira OM, et al. Effect of gender on postoperative outcomes and hospital stays after coronary artery bypass grafting. Ann Thorac Surg 1999;67:1097-103.

13. Kalish RL, Daley J, Duncan CC, et al. Costs of potential complications of care for major surgery patients. Am J Med Qual 1995;10:48-54.

14. Burns LR, Wholey DR. The effects of patient, hospital, and physician characteristics on length of stay and mortality. Med Care 1991;29:251-71.

15. Fleisher AG, Evans KG, Nelems B, et al. Effect of routine fibrin glue use on the duration of air leaks after lobectomy. Ann Thorac Surg 1990;49:133-4

16. Cooper JD. Technique to reduce air leaks after resection of emphysematous lung. Ann Thorac Surg 1994;57:1038-9.

17. Wain JC, Kaiser LR, Johnstone DW, et al. Trial of a novel synthetic sealant in preventing air leak after lung resection. Ann Thorac Surg 2001;71:1623-9.

18. Brunelli A, Al Refai M, Muti M, et al. Pleural tent after upper lobectomy: a prospective randomized study. Ann Thorac Surg 2000;69:1722-4. 


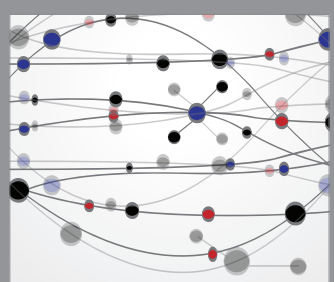

The Scientific World Journal
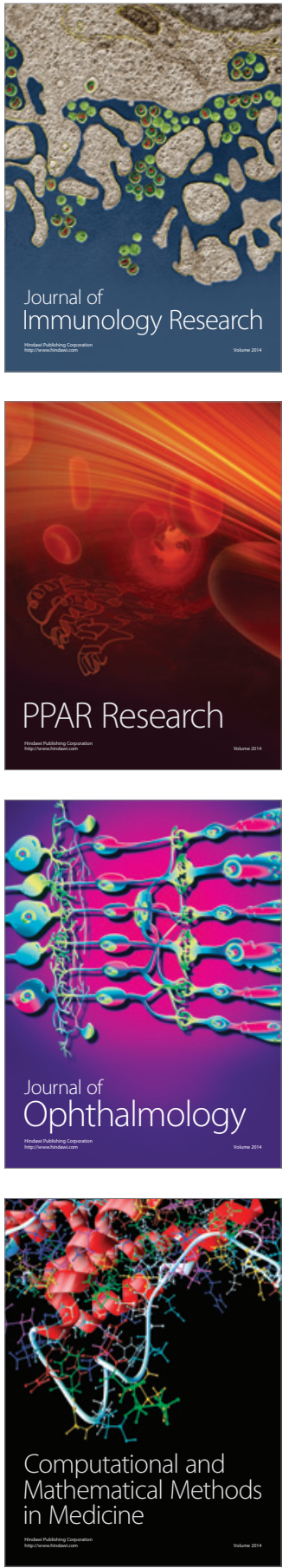

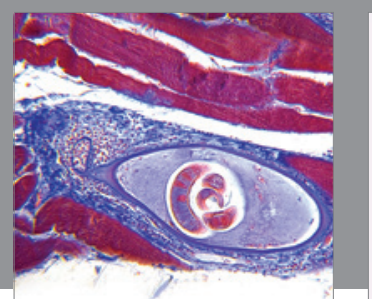

Gastroenterology Research and Practice

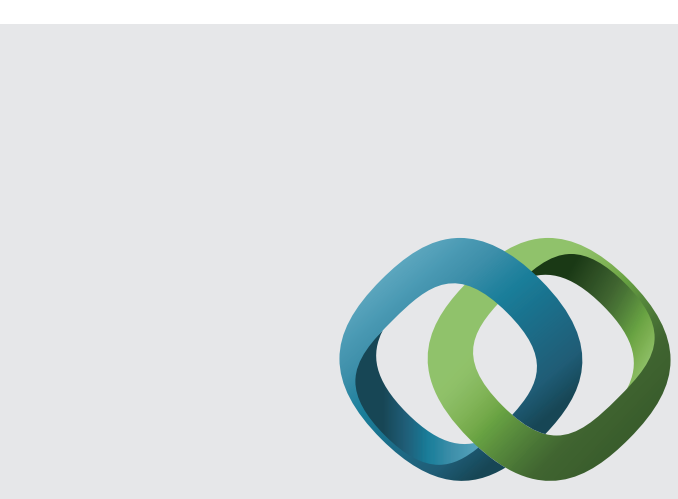

\section{Hindawi}

Submit your manuscripts at

http://www.hindawi.com
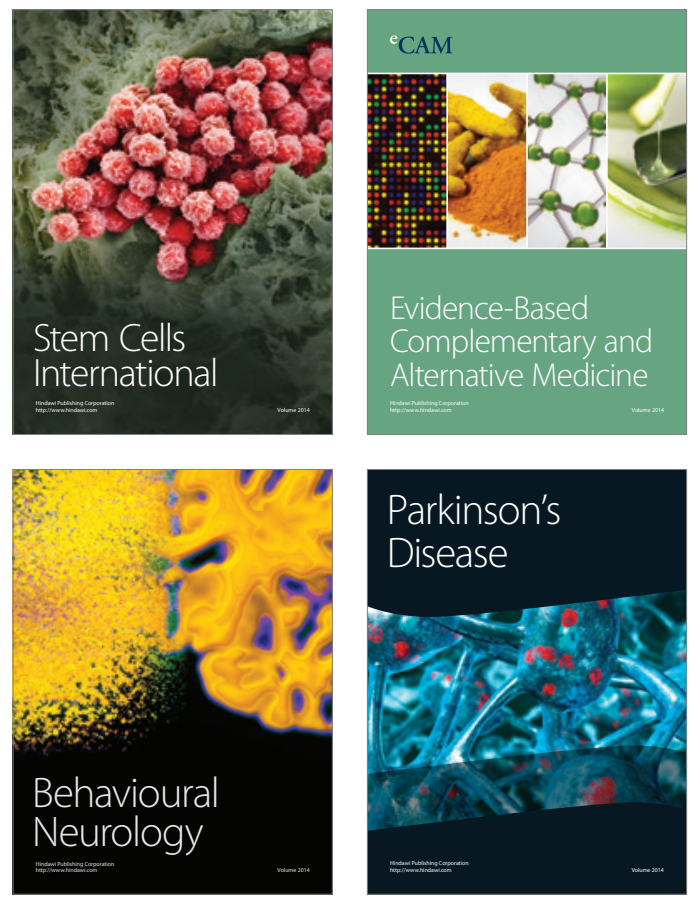
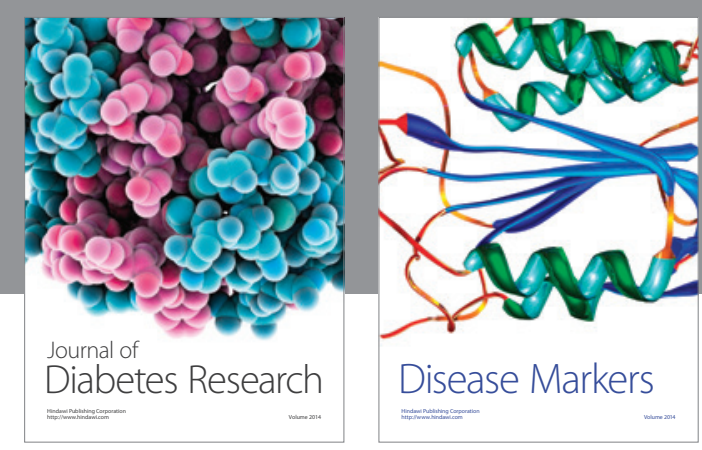

Disease Markers
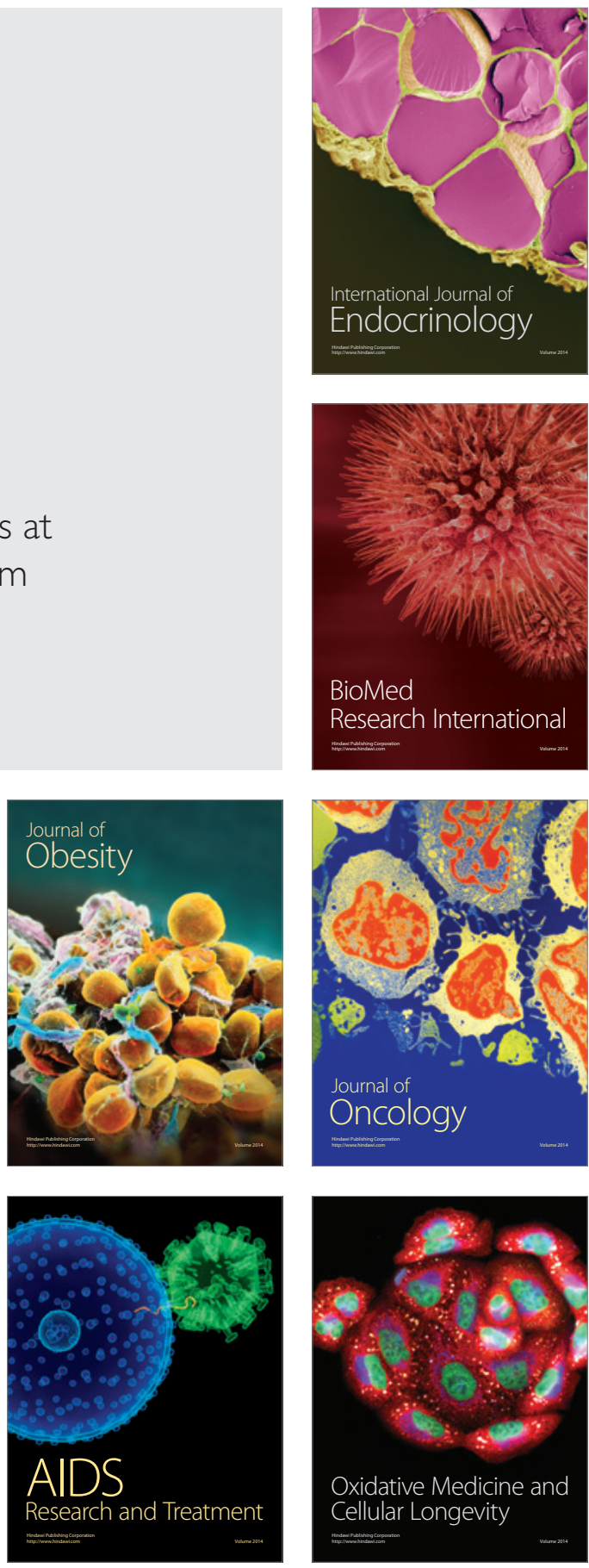